Abstracta Iranica Abstracta Iranica

Revue bibliographique pour le domaine irano-aryen

Volume 28 | 2007

Comptes rendus des publications de 2005

\title{
Fadlallah Astarabadi and the Hurufis. Oxford, Oneworld, 2005, xi-141 p., 1 carte, 2 ill. (Makers of the Muslim World)
}

\section{Orkhan Mir-Kasimov}

\section{(2) OpenEdition Journals}

Édition électronique

URL : http://journals.openedition.org/abstractairanica/12372

DOI : 10.4000/abstractairanica. 12372

ISSN : 1961-960X

Éditeur :

CNRS (UMR 7528 Mondes iraniens et indiens), Éditions de l'IFRI

\section{Édition imprimée}

Date de publication : 15 mai 2007

ISSN : 0240-8910

Référence électronique

Orkhan Mir-Kasimov, « Fadlallah Astarabadi and the Hurufis. Oxford, Oneworld, 2005, xi-141 p., 1 carte, 2 ill. (Makers of the Muslim World) », Abstracta Iranica [En ligne], Volume 28 | 2007, document 261, mis en ligne le 18 septembre 2007, consulté le 25 septembre 2020. URL : http://journals.openedition.org/ abstractairanica/12372 ; DOI : https://doi.org/10.4000/abstractairanica.12372

Ce document a été généré automatiquement le 25 septembre 2020.

Tous droits réservés 


\title{
Fadlallah Astarabadi and the Hurufis. Oxford, Oneworld, 2005, xi-141 p., 1 carte, 2 ill. (Makers of the Muslim World)
}

\author{
Orkhan Mir-Kasimov
}

1 Après Les textes persans relatifs à la secte des hurüfisis de Cl. Huart, paru en 1909, c'est la première monographie dans une langue occidentale consacrée au mouvement hurūfī, mouvement de tendance gnostique et messianique, fondé en Iran dans la deuxième moitié du XIVe s. par Faḍlallāh Astarābādī (m. 1394).

2 Les chapitres 1 à 3 traitent de la biographie de Faḍlallāh et de la période formative de la communauté hurūfî. L'apport des sources extérieures connues étant assez limité, toute tentative de reconstruction historique (S. Kiyā, A.Gölpınarll, H. Ritter, Y. Azhand...) s'appuie principalement sur les témoignages contenus dans les ouvrages de Faḍlallāh et de ses disciples. Ces derniers ont parfois tendance à présenter la vie de Faḍlallāh comme un itinéraire symbolique, où les événements réels et les rêves sont étroitement liés. Afin de pallier la subjectivité des sources, l'A. confronte systématiquement leurs données au contexte historique de l'époque. De ce point de vue, la connexion de Faḍlallāh avec d'autres mouvements d'inspiration messianique, comme celui des ŠayHiyye de Sabzevār, est particulièrement intéressante. Les versions inédites des rêves initiatiques de Faḍlallāh et le récit détaillé de son mariage sont autant d'exemples des faits nouveaux apportés par cette étude.

Les chapitres 4 et 5 contiennent un aperçu de la doctrine hurūfĩ. L'exposé est articulé autour de la notion de "métalangage" (metalanguage), terme introduit par l'A. pour désigner le langage divin créateur qui est au cœur de la pensée ḥurūfī. Le chapitre 4 concerne les trois grands thèmes de la doctrine hurūfī : la création du monde, la correspondance entre le microcosme et le macrocosme, et le temps avec les cycles prophétiques. Le chapitre 5 est consacré à la question du métalangage, principe universel et réalité ultime des choses. Faḍlallāh se voyait lui-même comme le lieu de 
manifestation (mazhar) de la totalité des éléments constituant le métalangage divin. Dès lors, sa mission consistait à préparer l'humanité à la manifestation imminente de la parole divine dans le monde, la manifestation qui marquera la fin des temps - d'où l'orientation apocalyptique de son enseignement.

Présenter la pensée hurūfĩ en quelques pages est un véritable défi. Remarquable par sa clarté et sa précision, l'exposé de Bashir est donc nécessairement trop sommaire par endroits. Par exemple, aucune mention n'est faite du mécanisme concret de la formation d'Adam, de l'univers matériel et du temps à partir des éléments premiers du langage primordial, ce qui empêche de saisir le caractère spécifiquement ḥurūfĩ de certains développements. Toutefois, malgré son volume très restreint, ce résumé de la doctrine comporte des données nouvelles (le rôle de Jésus comme initiateur d'un cycle interne de la prophétie, les exemples de lecture "métalinguistique" etc.), ainsi que des hypothèses originales (les signes spéciaux utilisés par les auteurs ḥurūfĩ comme une tentative de représentation directe des éléments du métalangage).

5 Dans les chapitres 6 et 7 l'A. revient à l'histoire du mouvement. Après la mort de Faḍlallāh, un nouvel rite se crée autour de sa tombe qui remplace désormais pour ses disciples la Mecque comme direction de la prière et lieu du pèlerinage. La communauté se disperse et se divise en plusieurs branches, dont l'activité sociale et politique s'éteint vers le milieu du $\mathrm{XV}^{\mathrm{e}}$ siècle. L'influence spirituelle et intellectuelle du hurufisme se propage cependant sur un vaste territoire incluant l'Iran, l'Inde et l'empire Ottoman, et se perpétue jusqu'à nos jours. L'ouvrage s'achève par une analyse du Livre Noir de l'écrivain turc Orhan Pamuk, un exemple d'interprétation contemporaine des idées hurūîi.

6 La monographie est parue dans une série destinée au large public. Les références ne sont donc pas aussi systématiques que dans une publication académique, et les notes de bas de page sont omises pour faciliter la lecture. Ceci n'enlève rien à la valeur scientifique de l'ouvrage, produit d'une longue recherche et d'une exploration minutieuse des sources, pour la plupart manuscrites. Par ailleurs, on trouvera les références en format ordinaire dans les articles universitaires de l'A. dont les titres sont indiqués dans la bibliographie. Cette dernière contient également une liste des principales études sur le hurūfisme, et est suivie d'un index général.

7 En conclusion, il s'agit d'une excellente introduction à l'histoire et la doctrine hurūfî, une synthèse des études antérieures enrichie d'éléments inédits.

\section{INDEX}

Thèmes : 7. Islam 
AUTEURS

ORKHAN MIR-KASIMOV

EPHE - Paris 